\title{
Behavioural effects of a tradable driving credit scheme: Results of an online stated adaptation experiment in the Netherlands
}

\author{
Nico Dogterom*, Dick Ettema, Martin Dijst \\ Faculty of Geosciences, Utrecht University, P.O. Box 80.115, 3508 TC Utrecht, The Netherlands
}

\section{A R T I C L E I N F O}

\section{Keywords:}

Tradable driving credits

Stated adaptation

Travel behaviour

Activity-travel patterns

Car use adaptation

\begin{abstract}
A B S T R A C T
There is increasing interest in the application of tradable credit schemes in the context of personal travel. To anticipate the short-term effects of a distance-based tradable driving credit (TDC) scheme, an innovative stated adaptation experiment has been conducted. Using an activity-based approach, Dutch participants who frequently commute by car could reschedule their car-based activities and alter the travel pattern they reported in an online travel diary for a full week. This paper presents the results of model estimations that describe the likelihood of changing car use and the number of kilometres driven in response to two TDC scenarios. Reductions were larger for those who experienced a loss under the measure compared to those who could expect a gain. Participants who worked more hours and who lived in non-urban areas showed lower car use reduction levels, whereas participants with middle incomes and who were 18-25 years old showed higher reduction levels. A car dependency measure was added to the models to assess how these effects are related to the availability of car use alternatives.
\end{abstract}

\section{Introduction}

Car traffic poses a range of problems in terms of congestion and pollution in many urban areas of the world, leading to major losses in the economic performance of cities and the quality of life of their inhabitants. Without adequate responses, undesirable consequences of growing traffic, such as time losses, social stress and harmful emissions, are expected to worsen given the steady increase in car travel demand and the considerable increase in car ownership in many rapidly developing economies (Girod et al., 2013; Pucher et al., 2007). Various policy responses to curb traffic volume and to influence car travel demand have been proposed at different spatial scales and in different contexts. Many of these initiatives have incorporated pricing mechanisms, as road pricing is believed to be an efficient tool for allocating scarce road space and making drivers pay for the negative externalities they impose on others (Pigou, 1920; Vickrey, 1969; Rouwendal and Verhoef, 2006). However, fierce societal and political resistance against pricing measures makes implementing initiatives that could affect car traffic flows at a significant scale difficult (Schade and Schlag, 2003).

The use of tradable driving credits (TDC) has been identified as a promising alternative method of managing the growth of car use in an effective and efficient yet potentially socially feasible way (Viegas, 2001; Goddard, 1999; Verhoef et al., 1997). In general, TDC schemes refer to market-based instruments that set a limit on aggregate car use and distribute credits, representing individual shares of this capped car use, to participating agents. These credits could be traded, so that credits flow to agents with the highest value of using the resource, while those with the lowest abatement costs are able to sell their excess credits.

Various TDC forms have been discussed in terms of scheme design and potential functioning (Goddard, 1999; Verhoef et al., 1997; Viegas, 2001; Raux and Marlot, 2005; Buitelaar et al., 2007). Other studies have theoretically explored TDC schemes from a

\footnotetext{
* Corresponding author.

E-mail address: N.J.Dogterom@uu.nl (N. Dogterom).
} 
mathematical perspective by modelling traffic flows and times under different credit allocation and traveller assumptions (e.g., Yang and Wang, 2011; Nie, 2012; Xiao et al., 2013; Bao et al., 2014). However, until now, little effort has been made to investigate drivers' responses to TDC schemes at the individual level. Yet, in order to anticipate TDC effects, an empirical approach that relates credit consumption to individual car travel patterns and socio-demographic characteristics is critically needed.

A number of studies has started to empirically approach responses to credit-based pricing schemes. Raux et al. (2015) empirically investigated the effects of a personal carbon trading scheme on travel behaviour alone, whereas Zanni et al. (2013), Parag et al. (2011) and Capstick and Lewis (2010) studied the effects of such a scheme on all energy consuming actions of individual households. Kockelman and Kalmanje (2005) explored drivers' reactions to a credit-based congestion pricing policy, in which credits were not formally tradable in a market but could be exchanged for money. However, these studies have generally investigated responses either in fictitious decision contexts or at a highly aggregated level. That is, they either elicited responses to scenarios that were based on hypothetical, non-experienced trips (e.g., Kockelman and Kalmanje, 2005) or presented options to respondents in which they could change their annual mileage or number of trips without a clear and direct connection to concrete activities and trips (e.g., Raux et al., 2015; Zanni et al., 2013; Parag et al., 2011; Capstick and Lewis, 2010). We argue, however, that placing TDC responses in the context of people's daily activity patterns leads to a more reliable understanding of TDC decision-making as a trade-off between credit availability and real activity and travel needs.

Therefore, this paper discusses the results of an online stated adaptation experiment that has been developed to anticipate shortterm responses to a TDC scheme using an activity-based approach (Axhausen and Gärling, 1992; Ettema and Timmermans, 1997). Participants reported their car-based activities for a full week and could reorganise this activity/trip pattern in response to two TDC scenarios. Using a sample of 308 Dutch car commuters, this study is the first to use a quantitative stated adaptation method that grounds TDC responses in actual trips and contextual characteristics on a large scale. In this paper, we specifically discuss the extent to which the investigated distance-based TDC scenarios leads to changes in vehicle kilometres travelled and how these changes relate to characteristics of the participants. In doing so, special attention is paid to the effect of facing a loss or a gain under these TDC scenarios, the influence of perceived car dependency and the role of participants' residential location, the latter being an aspect that studies on TDC have largely overlooked until now.

In the next section, we review theoretic and empirical work on TDC instruments. Section 3 describes the methodology and discusses the experiment, the scheme and the sample in more detail. Section 4 presents the results, and Section 5 provides a conclusion and discussion.

\section{Literature}

Tradable credit (TC) programmes offer regulators powerful tools to cope with the problem of the commons by rationing access to a resource and privatising access rights. In The Problem of Social Costs (1960), Coase argued that the lack of well-defined property rights causes the existence of externalities. These externalities could be eliminated if resource users could trade delineated private access rights in a market, which would lead to the efficient use of the resource regardless of the initial allocation of rights in situations with zero transaction costs and zero income effects. For a more thorough discussion of the theoretical foundations and practical details (e.g., its basic theorems, the issue of transaction costs, the issue of administration costs), we refer to Montgomery (1972), Baumol and Oates (1988), Hahn and Hester (1989), Hepburn (2006) and Tietenberg (2003). Compared to traditional pricing and taxing, the major advantages of TC schemes are that they provide regulators direct control over the quantity of total consumption and that price setting, which in the case of Pigouvian taxing is often problematic because of the need for a priori information about the precise valuation of the true costs of externalities and the demand and costs structures of the market, is left to the market (Verhoef et al., 1997). TC schemes have found several applications in upstream programmes in contexts such as air pollution control, fisheries, water resource management and land use control (Sovacool, 2011; Costello et al., 2008), but examples of implementation at the downstream, individual level are still absent.

Various authors, however, have started to conceptually explore the potential of TC in the personal transport domain. Verhoef et al. (1997) discussed several TC applications on the vehicle user side, as well as on the side of vehicle and fuel industries. Goddard (1999) proposed replacing the Mexico City non-driving-day vehicle restriction scheme with a more flexible tradable driving-day scheme. Examples of other proposals include mobility rights to drive in specific tolled areas and to ride public transport (Viegas, 2001), tradable fuel credits (Raux and Marlot, 2005; Crals et al., 2003) and, inspired by airport slot-allocation approaches, tradable road access rights (Buitelaar et al., 2007). For an elaborate review on various TC proposals in the transport domain, we refer to GrantMuller and Xu (2014) and Fan and Jiang (2013). At the same time, a parallel series of studies on the potential of so-called personal carbon trading schemes, targeting not only personal transport but all carbon emitting sources used by households, has emerged in the environmental literature (e.g., Starkey, 2012; Fawcett, 2010; Capstick and Lewis, 2010). The overall conclusions of these proposals are that TC schemes are theoretically efficient and could feasibly replace current road pricing and rationing initiatives, that widely encounter low acceptability rates (Jaensirisak et al., 2005; Schade and Schlag, 2003) and often lead to substantial undesirable side effects (Hao et al., 2011; Davis, 2008).

As a combination of control and pricing measures, TC schemes introduce flexibility and freedom of choice for drivers with respect to credit use within the limits of the cap on aggregate car travel. It is argued that the allocation of free credits to participants and the circulation of money among participants make TC schemes less likely to be perceived as a tax (Wadud, 2011). The opportunity to realise gains under the measure, as a positive incentive, could further enhance its acceptability and could function as an additional motivation for drivers to reduce their resource consumption. Moreover, the progressive nature of TC schemes - they will benefit groups with lower energy consumption/car use levels, which are usually lower-income groups - and the possibility for regulators to 
pursue certain distributional outcomes by means of credit allocation are believed to make a TC scheme more acceptable than a tax, as the distributional consequences seem to be a key determinant of the acceptability of pricing measures (Bristow et al., 2010; Mayeres and Proost, 2004). Further, from a more psychological perspective, TC proponents argue that individual TC schemes might realise additional behavioural changes over a tax via the mechanisms of budgeting (i.e., people wishing to remain within the suggested personal limit budget inspired by goal setting), increased individual engagement (i.e., people directly facing the consequences of their behaviour and exercising responsibility for their own credits) and increased collective involvement (i.e., the shaping of new social norms and a sense of collective action) (Parag et al., 2011; Fawcett and Parag, 2010; Capstick and Lewis, 2010).

These conceptual considerations have led researchers to start empirical research on the effects of TC schemes targeting personal transport. For a detailed discussion of this literature, we refer to Dogterom et al. (2017); here, we summarise the most important findings and methodological aspects. Empirical research started by exploring public opinion and general intentions. Kockelman and Kalmanje (2005) investigated attitudes towards and likely reactions to a credit-based congestion pricing scheme in the Austin area (TX, US) by presenting hypothetical situations in which respondents had to imagine travelling for a certain stretch under different credit availability assumptions. In a personal carbon trading (PCT) context, Wallace et al. (2010) and Parag et al. (2011) administered surveys in the UK in which they asked respondents to indicate their willingness to choose several carbon-saving actions. Both studies found higher willingness to choose home-based carbon-saving actions compared to travel-based carbon-saving actions.

Whereas these studies asked respondents to state intentions without relating these intentions to personal travel or carbon consumption patterns, other studies have developed research designs in which reported behaviour serves as input data for customised TC scenarios. Capstick and Lewis (2010) and Zanni et al. (2013), exploring the effects of PCT on all household carbon consumption, used a carbon footprint calculator to estimate participants' annual carbon consumption. Participants were then presented with a series of carbon-saving actions through an interactive computer-based simulation that enabled direct feedback on annual personal credit usage. Unfortunately, although both studies included travel-related carbon savings in the presented choice options, the relative impact of car use-specific options remains unclear from these studies.

Raux et al. (2015), studying a PCT scheme for car travel only, designed a stated preference experiment that included trade-offs on various suggested reduction levels, which were presented as a proportion of annual number of trips for different distance categories based on reported travel habits. With regard to duration, they found a higher willingness to reduce the number of shorter trips and, with regard to purpose, of commute and shopping trips. A more detailed approach was used by Harwatt et al. (2011), who analysed car use adaptations in response to a PCT measure based on participants' travel patterns collected through a weeklong travel diary. They found the PCT scheme to achieve larger reduction levels than a comparable carbon tax, with car trips being especially replaced by the train and cycle. However, as their study relied on a small sample no firm conclusions can be drawn from this study.

With regard to the effects of socio-demographic characteristics on transport-related TC behaviours, Kockelman and Kalmanje (2005) found that willingness to change car use decreased with age, vehicle ownership and income. A negative income effect was also reported by Zanni et al. (2013), who further found that respondents who were employed and living in larger households showed a higher willingness to change behaviour. An age effect was also reported by Raux et al. (2015), who found that people between 50 and 65 showed a higher propensity to maintain the status quo in response to a TC scenario than younger people. The authors included residential location in their model but did not find a significant effect. The limited number of studies that model the impact of sociodemographic characteristics on TC behaviours, together with the diverse results, clearly indicates a need for further research on possible associations in order to come to more conclusive and robust findings, a goal to which this study will contribute.

To conclude, methodologically, most of the empirical studies on transport-related TC behaviours discussed in this literature review measure car use reduction in a rather abstract manner, i.e., based on either hypothetical trip situations or highly aggregated data (defined in terms of annual distance/trips/carbon consumption). However, as these studies do not relate stated intentions to concrete, experienced trips and activities, it remains unclear how these reductions are to be realised and how they will precisely impact daily car use patterns. However, travel behaviour is intrinsically linked with people's needs, desires and obligations for out-ofhome activities, and travel adaptation capacities are highly structured by the space-time constraints of individual's activity patterns and available travel alternatives (Hägerstrand, 1970; Jones et al., 1983; Kitamura, 1988; Axhausen and Gärling, 1992; Timmermans, 2005; Dijst, 2009). Taking reported, actual trips and activities as the starting point of the analysis and conceptualising car use reduction as the outcome of dynamic trade-offs between activity needs, TC scheme characteristics and rescheduling opportunities and constraints, this study applies an activity-based approach to the study of responses to a tradable driving credit scheme.

In doing so, we expect to corroborate the age, income and household size effects found in the wider road pricing literature, i.e., the likelihood and the magnitude of change is expected to decrease among older participants, smaller households and higher incomes (c.f., Gehlert et al., 2011; Ubbels and Verhoef, 2005). We will also look into spatial context in this study, and in contrast to the findings from Raux et al. (2015), who only showed results for the Lyon (France) area, we expect to find a decreasing tendency to change and smaller changes for lower density residential areas, as we collect data from all parts of the Netherlands. This expectation is based on the finding that people in less-dense areas generally report higher levels of car use when measured by mode choice and distance travelled (Dieleman et al., 2002). Another important aim of this study is to assess the relative impact of gaining and losing under TC. Although participants theoretically could receive more credits than needed under a TC scheme, to date, only Zanni et al. (2013) have tried to explicitly capture the behavioural effects of facing a gain. They found that losses have a stronger impact on the decision to change car use than gains, with the probability of realising reductions increasing with larger losses and decreasing with larger gains. Based on this study and in line with prospect theory (Kahneman and Tversky, 1979; see Dogterom et al., 2017, for a detailed discussion of the potential implication of prospect theory on TC behaviours), we expect to find similar patterns of gains and losses determining the likelihood of changing car use and the magnitude of change. 


\section{Methodology}

\subsection{Stated adaptation experiment}

The experiment reported in this paper used a stated adaptation approach to analyse responses to a tradable driving credit (TDC) scheme. This approach refers to a category of surveys and experiments in which participants find their current behaviour confronted with a new, hypothetical situation, and are asked how they would react to such a situation. Most stated adaptation-based research on the impact of travel demand management instruments on travel behaviour therefore starts with collecting revealed behaviour by means of questionnaires, diaries, interviews or GPS tracking. The measure under examination is then introduced in a customised fashion, and individual reactions are recorded in an interactive simulation interview or experiment (Nijland et al., 2009; Arentze et al., 2004; Faivre D'Arcier et al., 1998; Lee-Gosselin, 1996). The stated adaptation experiment reported in this paper was entirely web based: both revealed car trips and responses to the TDC scenarios, which could be chosen from a pre-defined set of actions, were recorded through an online application that was specifically designed for this purpose.

The experiment's input consisted of participants' car trips over a full week. Although drivers might be given credits for a different period in a real-world TDC setting, we considered a week to be an appropriate period, as a longer period would have burdened the participants too much. Furthermore, as many activities that constitute the core of people's activity participation take place on a weekly basis, we believed that a weeklong experiment is well suited to shedding light on the TDC trade-offs made in the travel episodes that define normal daily life.

In the experiment, we investigated the effects of a distance-based TDC scheme, in which one credit represented one kilometre, irrespective of time and location. For the first scenario, a total reduction goal of $15 \%$ was defined in terms of kilometres driven by the sample. For the second scenario, the reduction goal was set at $30 \%$ to measure the effect of a smaller budget. Participants received equally sized budgets, implying that some participants were allocated more credits than they needed. In doing so, we could investigate potential differences in responses between participants with credit shortages and those with credit surpluses. Participants were randomly assigned one of three different price levels: $€ 0.10, € 0.15$ and $€ 0.20$ per credit (i.e., per kilometre). These prices are somewhat higher than the kilometre prices that have previously been used in Dutch kilometre pricing experiments (Ubbels and Verhoef, 2005; van Amelsfort et al., 2008), but we believed the different context of a TDC scheme warranted the use of higher prices because participants would only pay/gain if they exceeded a certain kilometre threshold. Further, because of the low expected shortterm elasticity of the price signals (Graham and Glaister, 2004; Goodwin et al., 2004), we chose to use prices that would exert sufficient pressure to make participants reconsider their trips, a strategy also adopted by Zanni et al. (2013) in their PCT experiment.

In their travel diaries, participants were required to record each trip they made as a car driver, irrespective of whether the car belonged to them. Each trip they made to complete an activity was defined as an individual trip, so trip chains comprising multiple destinations needed to be recorded as separate trips. Participants were instructed not to record business trips, i.e., trips made for work purposes other than the commute, as these trips are generally the employer's expenses and participants might have expected the same to apply in a TDC setting. Trips with a destination abroad were also excluded, as applying a national TDC scheme to these trips might have confused participants.

For each trip, participants needed to record the origin and destination location; activity type; flexibility of the trip/activity in terms of time, location and travel mode; and presence of passengers. Locations could be selected using a Google Maps interface and were saved under a personal description so that they could be easily selected again (Fig. 1a). Trip distances were calculated by Google Maps on the basis of shortest route by car. Although participants' actual driven route could deviate from this suggested route, it was not possible for them to change the route. This decision was made because changing routes would have required too much time and effort from the participants and because we believed routes would differ only slightly in terms of distance.

In the second part of the experiment, participants were presented with the TDC scenarios. After reading the instructions and the description of the adjustments participants could make, they were shown an overview page with information about their credits available, current credit usage and consequential financial balance (Fig. 1c). Participants could not lose or earn money in real, which is of course a drawback of the approach, however, the use of hypothetical choice contexts is common practice in much stated preference research. In response to the scenarios, participants could cancel trips, add trips and change trips in the same way as they entered trips in the travel diary. An additional option was the choice of a different travel mode: the public transport and slow mode (bike or walk) options did not require credits; the carpool option saved $50 \%$ of the original credit amount. The design of the experiment thus enabled participants to reorganise their trip schedule by, for instance, changing activity locations, combining/separating trips, or creating trip chains that use multiple travel modes (Fig. 1d). Adaptations immediately resulted in updated credit usage rates.

Participants needed to fill out a short questionnaire on socio-demographic characteristics prior to the travel diary. The experiment ended with a set of questions about attitudes towards personal car use and the TDC scheme.

\subsection{Sample}

This study took place in the Netherlands. Only people who frequently commuted by car were recruited to participate in the experiment because we wanted to explore the TDC scheme's impact on the class of drivers that contribute the most to congestion. Besides commuting at least 3 times per week by car, owning a car and having a fixed work location were defined as additional selection criteria. Having a fixed work location was required to enable an easy detection of a commute trip; owning a car was required because we believed that drivers with a company car might think that the credit costs would be (partly) borne by the employer and 


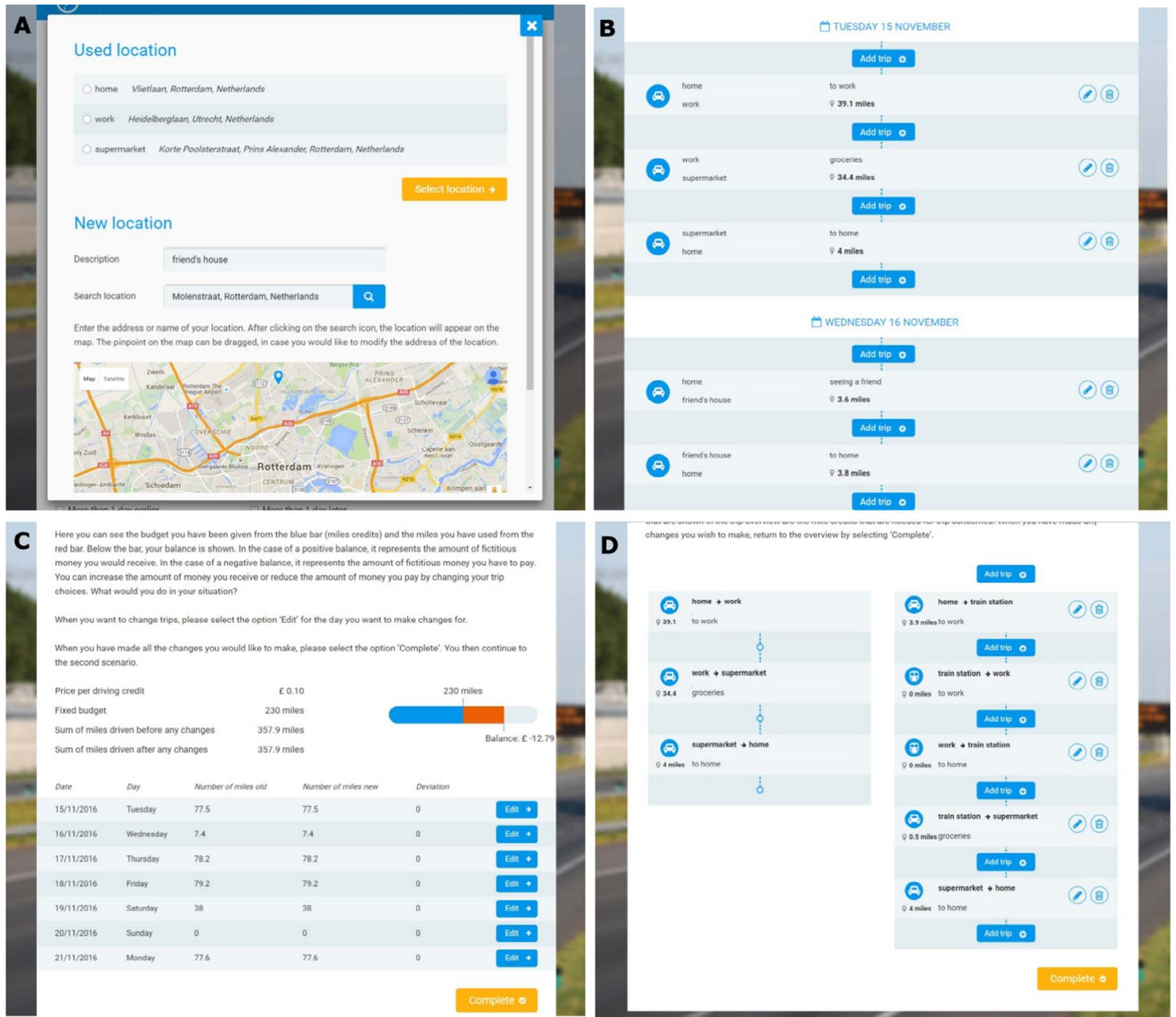

Fig. 1. Screenshots of the online application (English version) (a) When recording a trip in the travel diary, a new location could be entered or a previously used location could be selected. (b) A trip overview in the travel diary. (c) Presentation of kilometres driven per day, total credit availability and consequent financial balance in the adaptation part. (d) An original trip pattern and an adjusted trip pattern for a day in the adaptation part.

might thus take the experiment less seriously.

Participants were recruited by Panelclix/Euroclix, an online fieldwork company that has a nationwide online panel in the Netherlands. The usable sample for this paper includes 308 participants. The characteristics of the sample are given in Table 1 . It is important to bear in mind that because of the special selection criteria the sample is not representative for the population as a whole or for the class of commuters specifically. Especially, there is a gap in terms of education, with $63.3 \%$ of the sample being higher educated (university/higher professional), against 29.9\% of the society as a whole in the first half of 2017 (CBS, 2017 ). An overrepresentation of higher educated participants is something widely experienced in surveys, but also the use of our selection criteria might have played a role, as higher educated people might more often have a fixed working location. At the same time, the gap in educational levels might be attributed to the relative complexity of the experiment as lower-educated participants appeared to be relatively overrepresented in the drop-out group.

\subsection{Data collection process}

Members of the panel that expressed an interest in the study were directed to a webpage that showed detailed information about the TDC scheme and the procedure of the experiment. If they were still interested, and met the selection criteria, they could register themselves. In total, 1297 persons registered themselves and received an invitation to start the experiment in several waves from October-December 2015. Data collection was planned in weeks not influenced by the Autumn holiday and Christmas holiday, with the majority of the travel diaries being collected in November, a representative time period when it comes to traffic flows. Participants could access the experiment using a username and password and could start the experiment at their preferred time. After participants recorded their first trip, the 6 subsequent days for which we asked respondents to record their trips appeared in the trip 
Table 1

Sample composition $(\mathrm{N}=308)$.

\begin{tabular}{|c|c|c|c|}
\hline Characteristic & \multicolumn{2}{|c|}{ Operationalisation } & $\%$ \\
\hline \multirow[t]{2}{*}{ Gender } & Male & & 54.9 \\
\hline & Female & & 45.1 \\
\hline \multirow[t]{5}{*}{ Age } & $18-25$ & & 8.8 \\
\hline & $26-35$ & & 26.6 \\
\hline & $36-45$ & & 27.9 \\
\hline & $46-55$ & & 26.3 \\
\hline & $55-65$ & & 10.4 \\
\hline \multirow{4}{*}{ Household } & Single & without children & 18.5 \\
\hline & & With child(ren) & 4.9 \\
\hline & Couple & Without children & 34.4 \\
\hline & & With child(ren) & 42.2 \\
\hline \multirow[t]{3}{*}{ Educational level } & Lower $\mathrm{p}$ & & 4.9 \\
\hline & Middle & & 32.8 \\
\hline & Universi & & 63.3 \\
\hline \multirow[t]{4}{*}{ Work } & $1-19 \mathrm{~h}$ & & 7.1 \\
\hline & $20-29 \mathrm{~h}$ & & 15.3 \\
\hline & $30-39 \mathrm{~h}$ & & 44.2 \\
\hline & $40 \mathrm{~h}$ or & & 33.4 \\
\hline \multirow[t]{4}{*}{ Income (household disposable income per month) } & Less tha & & 27.9 \\
\hline & $€ 2000-€$ & & 39.9 \\
\hline & More th & & 19.8 \\
\hline & Would $\mathrm{r}$ & & 12.3 \\
\hline \multirow[t]{4}{*}{ Degree of density of municipality of residence } & Very str & & 18.8 \\
\hline & Strong & & 37.3 \\
\hline & Moderat & & 16.6 \\
\hline & Weak, $\mathrm{n}$ & & 25.2 \\
\hline
\end{tabular}

overview. A total of 918 participants started the experiment, of which 566 completed the whole experiment (61.7\%).

After close examination of the travel diaries before and after adaptation, a significant share of the trip patterns was incomplete (e.g., covering only one day or only one-way trips), inconsistent (e.g., having missing or duplicated trips), or otherwise not useful. Cases with a missing or duplicated trip shorter than 10 kilometres were included in the analysis because we permitted these small and isolated shortcomings in order to avoid wasting valuable travel and adaptation data. Further, we excluded cases that indicated car use reduction in scenario 1 but not in scenario 2 (25 cases), which very likely demonstrated the non-serious treatment of the second scenario. We also excluded 6 cases with more kilometres in the adapted travel diaries than in the original travel diaries, even in a credit shortage setting, as this behaviour could mean the addition of earlier forgotten trips. Furthermore, these cases pose practical problems in estimating tobit models. Two outlier cases reported a very high level of kilometres driven and were excluded from the analysis, as they caused the residuals of the dependent variable in the models to be non-normally distributed.

To set realistic, sample-specific budgets for the participants, the budgets were calculated based on the travel data reported in the diaries. For that reason, the adaptation part of the experiment could not be accessed until the budgets had been set based on a collection of travel diaries that showed a stable average distance per driver. Based on this stable distance figure, $15 \%$ and $30 \%$ reductions in the sample's kilometres driven resulted in individual budgets of 280 and 230 kilometre credits in scenarios 1 and 2 , respectively. After data collection and preparation, however, the average number of kilometres per participant was somewhat higher than calculated at the budget-setting stage because incomplete travel diaries, which generally had low reported distances, were excluded after all data had been collected. For the final sample, the budgets in scenarios 1 and 2 represent $17.5 \%$ and $32.2 \%$ reductions, respectively, of the total distance in kilometres driven by the sample.

\section{Results}

\subsection{Descriptive analysis}

Table 2 presents an overview of the average number of kilometres driven and the percentage of reduction in car kilometres

Table 2

Summary of reported car kilometres in the experiment.

\begin{tabular}{llll}
\hline & Original & Scenario 1 & Scenario 2 \\
\hline Kilometres (credits) in individual budgets & $\mathrm{n} / \mathrm{a}$ & 280 & 230 \\
Reduction goal & $\mathrm{n} / \mathrm{a}$ & $17.5 \%$ & $32.2 \%$ \\
Average number of car kilometres & 339.2 & 270.6 & 257.4 \\
Average realised kilometre reduction & $\mathrm{n} / \mathrm{a}$ & $20.2 \%$ & $24.1 \%$ \\
\hline
\end{tabular}


Table 3

Summary of participants' car use changes.

\begin{tabular}{|c|c|c|c|c|}
\hline \multirow[t]{2}{*}{ Percentage of participants that changed car use } & \multicolumn{2}{|c|}{$\begin{array}{l}\text { Scenario } 1 \\
62.3 \%\end{array}$} & \multicolumn{2}{|c|}{$\begin{array}{l}\text { Scenario } 2 \\
66.6 \%\end{array}$} \\
\hline & Loss & Gain & Loss & Gain \\
\hline Percentage of participants facing a loss or gain compared to the baseline situation & $54.6 \%$ & $45.4 \%$ & $64.9 \%$ & $35.1 \%$ \\
\hline Percentage of participants that changed car use & $78.6 \%$ & $42.9 \%$ & $78.5 \%$ & $44.4 \%$ \\
\hline
\end{tabular}

realised by the participants. Table 3 gives an indication of the share of reducers for the entire group of participants and for the subgroups facing a loss or a gain in a situation without change.

The realised reductions of $20.2 \%$ and $24.1 \%$ in scenarios 1 and 2, respectively, are fairly large; in scenario 1 , the total reduction exceeded the goal. Overall, approximately two-thirds of the participants reduced their car use, with the share of reducers in the second scenario being slightly higher than in the first scenario. A total of 99 participants (48.2\%) who changed their car use in the first scenario did not make additional reductions in the second scenario. This group might already have deployed their full car use reduction capacities in the first scenario. Although scenario 2 prosed a considerably higher reduction goal to the participants, there was only a slight increase of the total reduction. This finding might be explained by a cost hierarchy present in change options, implying that generally people first select alternatives that are less costly in terms of money and effort, and that additional change is more costly and therefore more difficult to achieve (Loukopoulos et al., 2006). It might also indicate a 'shock effect' in scenario 1, that is, the introduction of the measure has an effect apart from the total credits available (Dogterom et al., 2017). Of course, fatigue could also have played a role, as people might have been less motivated to take scenario 2 seriously because of the complexity and time required for the experiment.

Fig. 2 shows the percentages of participants that changed their car use and the reduction of kilometres as a proportion of the total kilometres driven, grouped by the gain and loss faced. Both scenarios show higher percentages of participants reducing in loss situations. On the loss side, the likelihood of changing car use increases in the first categories and tends to stabilise as losses become larger. On the gain side, the likelihood of changing car use decreases with larger gains. The same pattern is visible in the figures that show reduction as a proportion of total distance, with a stabilising reduction trend also appearing for those who gain. These patterns might be explained by the 'diminishing sensitivity effect', a robust phenomenon found in behavioural economics that means that the marginal effectiveness of losses or gains decreases with the size of the loss or gain (Kahneman and Tversky, 1979). Concerning the

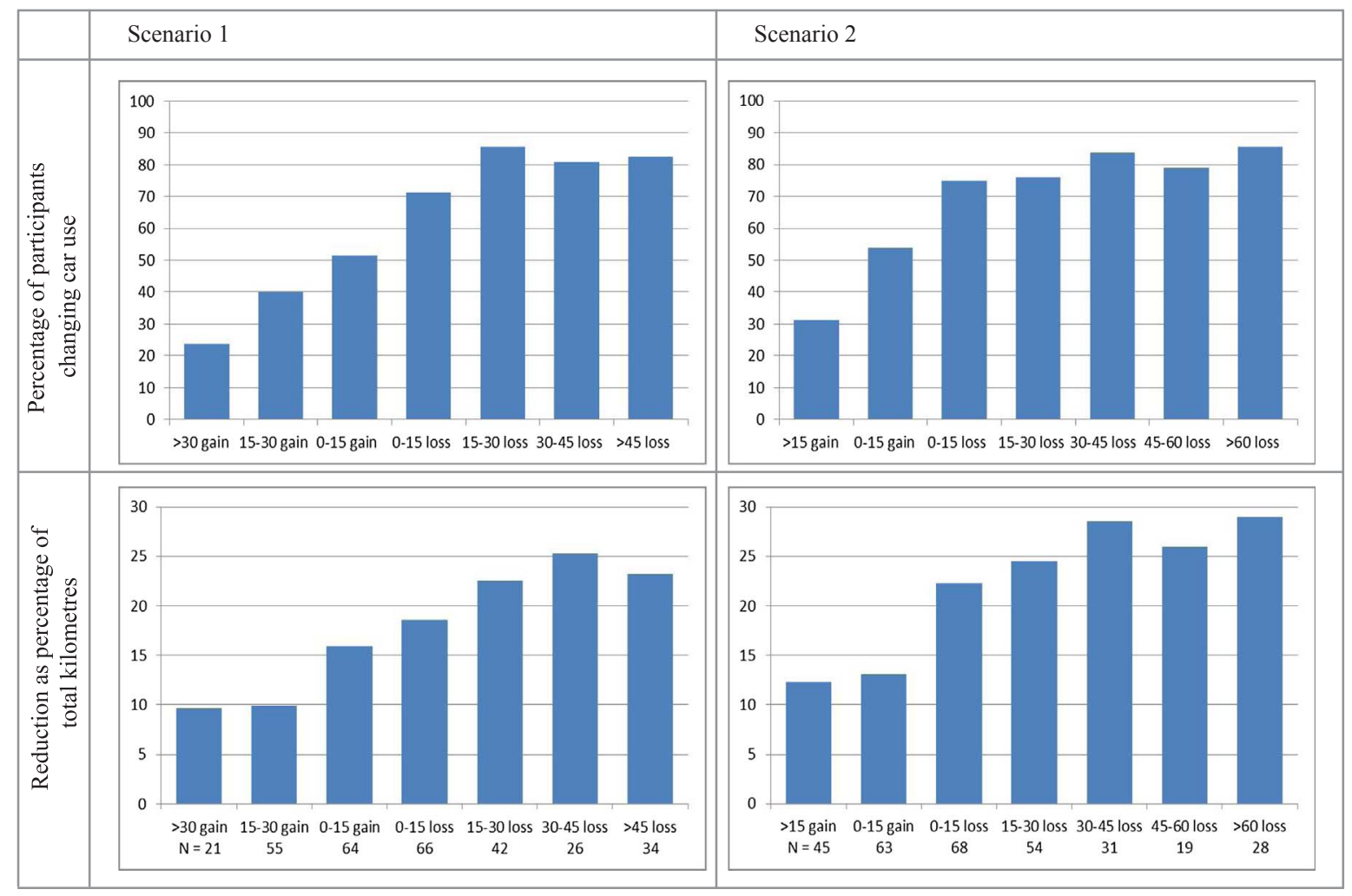

Fig. 2. Summary of change for different gain and loss groups. Gains and losses are listed in Euros. 
Table 4

Estimation results for likelihood to change (logit model).

\begin{tabular}{|c|c|c|c|c|c|c|c|c|}
\hline \multirow[t]{4}{*}{ Variable } & \multicolumn{4}{|l|}{ Scenario 1} & \multicolumn{4}{|l|}{ Scenario 2} \\
\hline & \multicolumn{2}{|l|}{ Total price } & \multicolumn{2}{|l|}{ Marginal price } & \multicolumn{2}{|l|}{ Total price } & \multicolumn{2}{|l|}{ Marginal price } \\
\hline & $\begin{array}{l}\text { Without car } \\
\text { dep. }\end{array}$ & With car dep. & $\begin{array}{l}\text { Without car } \\
\text { dep. }\end{array}$ & With car dep. & $\begin{array}{l}\text { Without car } \\
\text { dep. }\end{array}$ & With car dep. & $\begin{array}{l}\text { Without car } \\
\text { dep. }\end{array}$ & With car dep. \\
\hline & Coefficient & Coefficient & Coefficient & Coefficient & Coefficient & Coefficient & Coefficient & Coefficient \\
\hline Constant & $2.363^{\text {** }}$ & $4.013^{k * * x}$ & $2.544^{* *}$ & $4.141^{* k * k}$ & $3.046^{* *}$ & $5.076^{\text {k.k.k. }}$ & $3.231^{\text {*k }}$ & 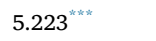 \\
\hline Male & $0.685^{* *}$ & $0.598^{*}$ & $0.660^{* * \hbar}$ & $0.573^{*}$ & 0.546 & 0.388 & 0.490 & 0.330 \\
\hline Age $26-35$ & $-1.290^{\text {skt }}$ & $-1.330^{* *}$ & $-1.454^{k \text { kik }}$ & $-1.454^{1 * *}$ & $-1.397^{* \star x}$ & $-1.460^{* *}$ & $-1.540^{* *}$ & $-1.553^{\text {*kt }}$ \\
\hline Age $36-45$ & $-1.497^{* \ldots k}$ & $-1.262^{*}$ & $-1.582^{2 k+k}$ & $-1.323^{k * *}$ & $-1.813^{\text {*.*.k }}$ & $-1.538^{* *}$ & $-1.887^{\text {whke }}$ & $-1.563^{\text {wke }}$ \\
\hline Age $46-55$ & -0.702 & -0.638 & -0.839 & -0.724 & -0.965 & -0.856 & -1.106 & -0.928 \\
\hline Age $56-65$ & -0.670 & -0.279 & -0.722 & -0.260 & -1.237 & -0.831 & -1.286 & -0.805 \\
\hline Single & -0.125 & -0.155 & -0.191 & -0.186 & 0.012 & -0.016 & -0.066 & -0.065 \\
\hline Number or children & $0.346^{* \star}$ & $0.340^{k *}$ & $0.328^{* *}$ & $0.343^{k * k}$ & $0.309^{* *}$ & $0.309^{*}$ & $0.295^{*}$ & $0.311^{*}$ \\
\hline Middel education & -0.412 & -0.279 & -0.271 & -0.074 & -0.630 & -0.558 & -0.492 & -0.386 \\
\hline Higher education & -0.047 & -0.039 & 0.175 & 0.189 & -0.290 & -0.345 & -0.064 & -0.132 \\
\hline Work $20-29 \mathrm{~h}$ & -0.713 & -0.688 & -0.719 & -0.692 & -0.338 & -0.065 & -0.327 & -0.036 \\
\hline Work 30-39h & -0.928 & -0.848 & -0.844 & -0.775 & -0.733 & -0.476 & -0.633 & -0.389 \\
\hline Work $>40 \mathrm{~h}$ & $-1.190^{*}$ & -0.965 & $-1.182^{*}$ & -0.977 & -0.752 & -0.276 & -0.683 & -0.242 \\
\hline Income $€ 2000-€ 3500$ & 0.455 & 0.313 & 0.438 & 0.262 & $0.982^{k * *}$ & $0.891^{* * *}$ & $0.958^{* k}$ & $0.818^{* *}$ \\
\hline Income $>€ 3500$ & -0.162 & -0.402 & -0.184 & -0.437 & 0.139 & -0.123 & 0.110 & -0.180 \\
\hline $\begin{array}{l}\text { Would rather not say } \\
\text { income }\end{array}$ & -0.355 & -0.305 & -0.377 & -0.300 & -0.386 & -0.353 & -0.416 & -0.364 \\
\hline $\begin{array}{l}\text { Number of cars in } \\
\text { household }\end{array}$ & 0.086 & 0.334 & 0.089 & 0.328 & -0.160 & 0.123 & -0.175 & 0.094 \\
\hline $\begin{array}{l}\text { Strongly urbanised } \\
\text { municipality }\end{array}$ & 0.069 & 0.062 & -0.096 & -0.054 & -0.144 & -0.259 & -0.328 & -0.394 \\
\hline $\begin{array}{l}\text { Moderately urbanised } \\
\text { municipality }\end{array}$ & 0.172 & 0.283 & 0.067 & 0.221 & -0.324 & -0.350 & -0.424 & -0.403 \\
\hline $\begin{array}{l}\text { Weakly/non-urbanised } \\
\text { municipality }\end{array}$ & $-0.734^{*}$ & -0.667 & $-0.787^{*}$ & -0.721 & $-0.894^{* *}$ & $-0.909^{*}$ & $-0.949^{* *}$ & $-0.973^{* * *}$ \\
\hline $\begin{array}{l}\text { No alternative to car use } \\
\text { (car dep.) }\end{array}$ & & $-0.462^{\text {wikik }}$ & & $-0.481^{\text {knd }}$ & & $-0.559^{k \ldots k x}$ & & $-0.575^{k k^{k * k}}$ \\
\hline Total loss & $0.015^{*}$ & $0.020^{* * *}$ & & & $0.014^{*}$ & $0.020^{\text {**ke }}$ & & \\
\hline Total gain & $-0.071^{\text {stikex }}$ & $-0.081^{* * * k}$ & & & $-0.101^{\text {*k*ke }}$ & $-0.123^{* * * *}$ & & \\
\hline $\begin{array}{l}\text { Kilometres travelled } \\
\text { (loss) }\end{array}$ & & & 0.001 & $0.002^{* * k}$ & & & 0.001 & $0.002^{* * k}$ \\
\hline $\begin{array}{l}\text { Kilometres travelled } \\
\text { (gain) }\end{array}$ & & & $-0.012^{* k * k}$ & $-0.014^{* * * * *}$ & & & $-0.017^{* \ldots / k}$ & $-0.020^{\text {skek }}$ \\
\hline Credit price is $€ 0.15$ & & & -0.224 & -0.024 & & & -0.249 & -0.037 \\
\hline Credit price is $€ 0.20$ & & & 0.221 & 0.169 & & & 0.209 & 0.166 \\
\hline Log-likelihood & -162.905 & -149.003 & -161.339 & -146.967 & -154.221 & -137.273 & -153.071 & -135.814 \\
\hline $\mathrm{R}^{2}$ (adjusted) & 0.202 & 0.270 & 0.209 & 0.280 & 0.214 & 0.301 & 0.220 & 0.308 \\
\hline $\mathrm{X}^{2}(\mathrm{df})$ & $82.22(21)^{3 \times k+}$ & $110.03(22)^{* k+k}$ & $85.35(23)^{3.1 \times 2 k}$ & $114.10(24)^{2, k+k}$ & $84.11(21)^{k * 3 x}$ & $118.01(22)^{2,2 x+k}$ & $86.41(23)^{k-k \cdot k}$ & $120.93(24)^{3.2 x+x}$ \\
\hline
\end{tabular}

\footnotetext{
$* p<.10$.

$* * p<.05$.

$* * * p<.01$
}

size of reduction, based on several empirical studies in the context of personal carbon trading, Zanni et al. (2013) suggest that there appears to be an overall upper limit of $20 \%$ for short-term carbon consumption reduction. The presence of an upper limit, albeit somewhat more than $20 \%$, also seems to appear in our kilometre reduction data.

After these general observations, the following section provides a more detailed investigation of participants' likelihood of changing car use and the size of reduction by modelling these variables as dependent on various participant characteristics.

\subsection{Multivariate analysis}

\subsubsection{Likelihood of changing car use}

Because the choice whether or not to change the reported car use in response to the presented TDC scheme is binary, logit regression models have been used to estimate the model parameters. Table 4 shows the results for the included parameters for both scenario 1 and scenario 2. Separate models have been estimated for total price, which is either a loss or a gain, and marginal price, i.e., the price per credit. These models were also estimated with a general car dependency measure added, which enables the identification of possible mediation effects of perceived car use flexibility on the association between socio-demographic characteristics and car use reduction. Participants' level of car dependency was measured in the final questionnaire by a statement that reads: 'I do not have alternatives for my car use' (completely disagree (1) - completely agree (7)). 
Several socio-demographic characteristics have statistically significant impacts on the likelihood of changing car use in response to the TDC measure. In all models, participants aged 26-45 are less likely to change their car use than participants aged 18-25. This is consistent with other road pricing studies that have found that younger people are more likely to adjust their car use (Raux et al., 2015; Gehlert et al., 2011). Because the effect remains after controlling for car dependency, explanations might lie in younger people having more activity rescheduling options because they might have fewer household responsibilities. In scenario 1, males are more likely to change their car use, but this effect is absent in scenario 2. Explanations for this result are elusive and the literature provides mixed results on gender effects. Polk (2004) found a higher general likelihood of changing car use among women, and Mokhtarian et al. (1997) found the same when the behaviour was specified as a response to congestion. However, Odeck and Bråthen (1997), in the context of Oslo road tolls, reported that men were more inclined to agree with the statement that tolls had made them reduce their car use. In follow-up studies, we will analyse activity types, trip attributes and alternatives in more detail, possibly providing more insight into the reasons behind the gender difference we found.

The number of children has a significant, positive effect, meaning that the likelihood of changing car use increases with the number of children living in the household, even when controlling for car dependency. Other studies have also found that the presence of children positively affects the likelihood of adapting car use in response to pricing measures (Zanni et al., 2013; Gehlert et al., 2011; Ubbels, 2006). One explanation might be that the number of children increases the number and diversity of household activities that require the car, therefore increasing the potential for reduction. Further, tasks can be more easily redistributed within larger households, especially when children are less dependent and can organise their own travel patterns.

Working $40 \mathrm{~h}$ or more per week negatively impacts the likelihood of changing car use at a $10 \%$ significance level, but only in scenario 1 and without controlling for car dependency. There is an income effect in scenario 2 , as those with middle incomes are more likely to change than those in the lowest income group. This finding is somewhat surprising as willingness to adapt car use in response to pricing measures is commonly found to decrease with income (Washbrook et al., 2006; Ubbels and Verhoef, 2005; Kockelman and Kalmanje, 2005; Rienstra et al., 1999). A possible explanation is that people in the lower-income group are more constrained in their choices with regard to activity scheduling (Clay and Mokhtarian, 2004).

With regard to residential area, the models show that residing in a weakly or non-urbanised area negatively impacts the likelihood of changing car use compared to living in a highly urbanised area. This effect is more pronounced in the second scenario, where the effect remains significant even after controlling for car dependency. In addition to being more car dependent, those who live in more rural areas might have fewer opportunities for combining trips or choosing alternative activity locations. As expected, the car dependency measure is highly significant in all models and indicates a higher propensity to maintain the status quo when fewer car use alternatives are available.

The effects of facing a loss or a gain are largely intuitive: the likelihood of change increases with larger losses and decreases with larger gains, not only because people facing larger gains might be more easily satisfied with the status quo but also because these people simply have fewer kilometres to reduce. Interestingly, the models based on marginal price, in which total price has been distinguished into a price per kilometre variable and total number of kilometres travelled variable, show that participants that face a higher credit price are not significantly more prepared to change their car use.

\subsubsection{Size of reduction}

Another series of models has been estimated to assess the impact of participants' characteristics on the magnitude of car use reduction in response to the presented TDC schemes, as measured by the number of kilometres reduced. Left-censored tobit models have been estimated because the dependent variable includes many zero value observations (approximately one-third did not reduce their car use). Table 5 presents the results of the parameter estimations.

The amount of time spent working and the density of the residential area are the only variables that have significant effects in both scenarios. The number of kilometres reduced decreases with the number of hours worked per week. This is a natural outcome, as one might expect working trips to be the least sensitive to road pricing (Ubbels and Verhoef, 2005) and those spending more hours per week on working having a tighter activity-time budget. Indeed, the inability to reduce the number of kilometres driven among those with the most working hours seems to be largely associated with the inability to reduce driving as the effect disappears when controlling for car dependency. Similar to the likelihood of changing car use, living in a weakly or non-urbanised area has also a negative effect on the size of reduction compared to living in a highly urbanised area. The effect remains after controlling for car dependency, although it is somewhat weaker. As mentioned in the previous subsection, this result indicates that those living in rural areas might face more constraints in terms of trip chaining and the choice of alternative activity locations.

Age and income start to have an impact on reduction size in scenario 2. All participants over 25 years old show smaller changes than those in the 18-25 age category, indicating that the youngest participants are able to realise larger additional changes under a tighter credit budget. The effect remains after controlling for car dependency, suggesting that other factors might play a role here. Possible explanations might include younger participants' higher price sensitivity, higher activity and schedule flexibility and greater openness to change. With regard to income, participants with middle incomes report larger reductions compared to those with lower incomes; however, in contrast to the willingness-to-change models, the effect vanishes after controlling for car dependency. This result suggests that the higher car dependency of participants with disposable monthly incomes up to €2000 does not impact the decision to change, but it constrains the number of kilometres that they are able to reduce.

As expected, the car dependency measure itself is highly significant, having a negative impact on the reduction size. The variables that indicate total price (total loss/gain, kilometres lost/gained) are highly significant, with the magnitude of the reduction increasing with greater losses and decreasing with greater gains, which are expected outcomes. Again, marginal price has no effect on the size of reduction. We included a non-linear total price term in the model to test for a 'diminishing sensitivity' effect, but as this term was not 
Table 5

Estimation results for number of reduced car kilometres (tobit model).

\begin{tabular}{|c|c|c|c|c|c|c|c|c|}
\hline \multirow[t]{4}{*}{ Variable } & \multicolumn{4}{|l|}{ Scenario 1} & \multicolumn{4}{|l|}{ Scenario 2} \\
\hline & \multicolumn{2}{|l|}{ Total price } & \multicolumn{2}{|l|}{ Marginal price } & \multicolumn{2}{|l|}{ Total price } & \multicolumn{2}{|l|}{ Marginal price } \\
\hline & $\begin{array}{l}\text { Without car } \\
\text { dep. } \\
\text { Beta }\end{array}$ & With car dep. & $\begin{array}{l}\text { Without car } \\
\text { dep. }\end{array}$ & With car dep. & $\begin{array}{l}\text { Without car } \\
\text { dep. }\end{array}$ & With car dep. & $\begin{array}{l}\text { Without car } \\
\text { dep. }\end{array}$ & With car dep. \\
\hline & & Beta & Beta & & & & & Beta \\
\hline Constant & $123.729^{* *}$ & $201.872^{\text {k***}}$ & $146.292^{\text {** }}$ & $212.738^{\text {kekk }}$ & $201.500^{k * * *}$ & $285.559^{\text {*k*k }}$ & $217.419^{\text {knk*x }}$ & $287.070^{\text {**k⿲丿丨 }}$ \\
\hline Male & 32.492 & 21.735 & 27.049 & 16.169 & 26.434 & 14.264 & 20.157 & 8.150 \\
\hline Age 26-35 & -44.450 & -37.872 & -45.715 & -37.051 & $-87.800^{* k * x}$ & $-80.403^{k x * x}$ & $-90.827^{* k * \pi}$ & $-81.355^{* * * x}$ \\
\hline Age $36-45$ & -45.024 & -13.855 & -41.159 & -10.005 & $-95.142^{k \ldots * k}$ & $-58.204^{* *}$ & $-92.022^{k+k * k}$ & $-55.201^{* k}$ \\
\hline Age $46-55$ & -20.203 & -6.262 & -19.446 & -4.398 & $-71.911^{k * k}$ & -55.360 & $-72.819^{k \ldots k}$ & $-55.171^{*}$ \\
\hline Age 56-65 & -1.304 & 24.222 & 5.366 & 31.064 & $-66.583^{*}$ & -36.687 & $-61.552^{*}$ & -31.479 \\
\hline Single & -23.081 & -26.167 & -28.500 & -29.773 & -13.827 & -17.377 & -20.554 & -22.007 \\
\hline Number or children & 12.519 & 8.909 & 10.774 & 7.791 & 4.879 & 0.746 & 3.146 & -0.282 \\
\hline Middel education & -9.967 & -7.911 & -11.168 & -5.204 & -12.354 & -7.521 & -11.618 & -2.913 \\
\hline Higher education & 4.021 & 3.984 & 9.018 & 10.102 & -1.600 & 1.086 & 7.337 & 10.843 \\
\hline Work $20-29 \mathrm{~h}$ & $-64.950^{*}$ & -48.153 & $-66.683^{*}$ & -47.414 & $-70.331^{*}$ & -52.189 & $-74.944^{* k t}$ & -52.912 \\
\hline Work $30-39 \mathrm{~h}$ & $-66.841^{*}$ & -45.445 & $-61.387^{*}$ & -38.041 & $-77.728^{k * k}$ & $-54.316^{*}$ & -72.930 & -47.143 \\
\hline Work $>40 \mathrm{~h}$ & $-78.770^{* *}$ & -47.808 & $-78.936^{k * k}$ & -46.272 & $-75.692^{* *}$ & -40.794 & $-76.403^{k x k}$ & -39.416 \\
\hline Income $€ 2000-€ 3500$ & 15.011 & -1.276 & 14.445 & -4.003 & $49.018^{* * *}$ & 30.920 & $49.939^{* *}$ & 29.693 \\
\hline Income $>€ 3500$ & 29.645 & 13.045 & 21.180 & 2.694 & 42.325 & 24.815 & 34.687 & 15.305 \\
\hline $\begin{array}{l}\text { Would rather not say } \\
\text { income }\end{array}$ & 4.063 & 5.452 & -2.325 & 0.871 & 1.679 & 4.713 & -4.092 & 0.703 \\
\hline $\begin{array}{l}\text { Number of cars in } \\
\text { household }\end{array}$ & -12.478 & 1.399 & -15.356 & -1.656 & -22.095 & -6.365 & $-24.728^{*}$ & -9.431 \\
\hline $\begin{array}{l}\text { Strongly urbanised } \\
\text { municipality }\end{array}$ & 11.818 & 15.959 & 2.631 & 10.499 & -13.211 & -7.287 & -24.246 & -14.037 \\
\hline $\begin{array}{l}\text { Moderately urbanised } \\
\text { municipality }\end{array}$ & -14.130 & -7.120 & -14.306 & -3.127 & -35.085 & -26.615 & -36.982 & -23.978 \\
\hline $\begin{array}{l}\text { Weakly/non-urbanised } \\
\text { municipality }\end{array}$ & $-51.352^{k *}$ & $-41.133^{*}$ & $-52.142^{* *}$ & -40.385 & $-62.980^{k * k}$ & $-49.716^{k *}$ & $-63.985^{\text {k*kx }}$ & $-49.317^{* * *}$ \\
\hline $\begin{array}{l}\text { No alternative to car use } \\
\text { (car dep.) }\end{array}$ & & $-28.981^{*}$ & & $-29.842^{\text {the }}$ & & $-32.837^{\text {thex }}$ & & $-33.403^{k \ldots k x}$ \\
\hline Total loss & $1.896^{\text {k*kik}}$ & $2.191^{k+\pi * k}$ & & & $2.036^{* \ldots x}$ & $2.323^{\text {thex }}$ & & \\
\hline Total gain & $-4.639^{\text {sike. }}$ & $-4.629^{* \cdots *}$ & & & $-6.119^{* * k}$ & $-6.071^{* * *}$ & & \\
\hline $\begin{array}{l}\text { Kilometres travelled } \\
\text { (loss) }\end{array}$ & & & $0.257^{* 2 k+k}$ & $0.319^{* * * * *}$ & & & $0.268^{* * * *}$ & $0.329^{* \ldots * k}$ \\
\hline $\begin{array}{l}\text { Kilometres travelled } \\
\text { (gain) }\end{array}$ & & & $-0.768^{* * * *}$ & $-0.740^{* k * k}$ & & & $-1.048^{* \ldots * x}$ & $-0.983^{3 k * k}$ \\
\hline Credit price is $€ 0.15$ & & & -29.541 & -12.786 & & & -23.592 & -6.245 \\
\hline Credit price is $€ 0.20$ & & & 2.519 & 2.840 & & & 21.628 & 21.728 \\
\hline Log-likelihood & -1269.191 & -1247.250 & -1266.349 & -1243.262 & -1344.337 & -1313.891 & -1342.788 & -1311.945 \\
\hline $\mathrm{R}^{2}$ (adjusted) & 0.045 & 0.061 & 0.047 & 0.064 & 0.049 & 0.070 & 0.050 & 0.072 \\
\hline $\mathrm{X}^{2}(\mathrm{df})$ & $119.18(21)^{* * * *}$ & $163.06(22)^{* x+2 k x}$ & $124.86(23)^{k+k x k}$ & $171.04(24)^{k+k \cdot k}$ & $137.13(21)^{* * * * x}$ & $198.02(22)^{* * * *}$ & $140.23(23)^{k+k \cdot k}$ & $201.91(24)^{k \ldots k n}$ \\
\hline
\end{tabular}

$* p<.10$.

$* * p<.05$.

$* * * p<.01$.

significant and did not improve the model, this term has not been included in the model presented here.

\section{Conclusion and discussion}

This paper explored the behavioural effects of a TDC scheme, focusing on its impact on the car use patterns of frequent commuters in the Netherlands. An online stated adaptation experiment was designed in which participants could reorganise their activity/trip pattern for a full week in response to two kilometre-based TDC scenarios, the second scenario simulating a further reduced credit availability. Such a stated adaptation approach forced participants to reconsider their car use within the experienced framework of concrete trips, activity needs and situational travel alternatives and constraints, which is largely lacking in the existing TDC research. In this paper, we examined the likelihood of changing car use and the size of realised car use reduction, and we related these figures to participants' socio-demographic characteristics, density level of residential area and perceived car dependency.

The results suggest a substantial car use reduction under the TDC measure. Approximately two-thirds of the participants adapted their car use, and total reductions of $20.2 \%$ and $24.1 \%$ in terms of vehicle kilometres driven by the sample were achieved in scenarios 1 and 2, respectively. Whereas the willingness to change figures are in line with other travel-related tradable credit schemes, the magnitude of change is somewhat larger than what is found in comparable tradable credit studies (Raux et al., 2015; Zanni et al., 2013; Parag et al., 2011). 
At first glance, the reduction levels suggest that a TDC measure could well compete with other road pricing measures. Other Dutch road pricing studies report lower car change figures, with up to $15 \%$ of trips adjusted under a time-differentiated kilometre charge (Tillema, 2007; Ubbels and Verhoef, 2005); however, differences in research design, pricing scheme (charge level, level of differentiation within the scheme) and measurement of change (adjusted kilometres or trips) call for cautious comparison of these figures. Studies that directly compare behavioural change under personal carbon trading schemes and equivalent taxes show mixed results. Whereas Raux et al. (2015) and Zanni et al. (2013) find no significant differences between the measures, Parag et al. (2011) and Harwatt et al. (2011) report higher mileage reductions under a trading scheme. With regard to public support, studies that have investigated public perceptions of both credit schemes and conventional road pricing indicate higher levels of support for the credit scheme (Harwatt et al., 2011; Bristow et al., 2010; Kockelman and Kalmanje, 2005).

It should be noted that the findings of our study, similar to most of the studies mentioned above, are based on an experimental design that uses individual-based and 'static' scenarios with fixed price levels. Of course, in a real tradable credit scheme, using a dynamic market, the reduction in car travel volume would always equal the predefined cap, which makes it radically different from road taxes. What our study shows is that a TDC scheme in which people can trade their credits for a certain fixed price - prices that do not deviate much from kilometre prices used or proposed in conventional road pricing programmes - can already mobilise a considerable preparedness to adapt present car use behaviours. This in an important finding in terms of expected TDC market dynamics, as credit prices in a real market would depend on people's price sensitivity. Yet, it is crucial that future research starts to examine the more dynamic aspects of TDC schemes, such as decision-making under variable credit prices and trading behaviours, to enhance our understanding of the effects of a realistic credit trading scheme. Interactive simulations and experimental games are promising research avenues in this respect.

From a policy perspective, another TDC characteristic that makes the measure radically different from conventional road pricing is that the concept is based on revenue-neutrality. This is believed to enhance public support, but at the same time, it deprives authorities from valuable resources. Alternatively, credits could be sold in an auction, rather than through grandfathering (Nie, 2012; Santos et al., 2010; Cramton and Kerr, 2002). Selling credits in an auction would not only raise revenues, that could lower existing car taxes and alleviate tax distortions, but would also take benefit from the fact that the impact of TDC is larger for those that have to buy credits, making the measure more effective. Yet, the consequences for public support should be carefully appreciated, when the aim is to identify the 'best' scheme, considering effectiveness, efficiency and social feasibility.

The same applies when it comes to the desired scope and differentiation of the TDC scheme. The scheme investigated in this explorative study is rather simple, as it covers only distance in a non-differentiating way. A scheme in which the need for credits is dependent on time, location, characteristics of the car, etc., might be better suited to guarantee non-congested roads and to also tackle various other externalities of personal car transport efficiently. At the same time, there seems to be a tension between the theoretical desirability of a high level of differentiation and flexibility of price structures and the ability of agents to respond in a rational and effective way (see Bonsall et al., 2007; Franke and Kaniok, 2013).

When looking at the factors affecting car use change under TDC, many road pricing studies to date do not explicitly connect car use changes with people's ability to choose alternatives to their car use. However, by including a car dependency measure in our analysis, we were able to explicitly model the mediating effect of car dependency - measured as a perceived, general car dependency indicator - when we estimated the effects of socio-demographic factors on car use reduction. The effects of working hours and income disappeared (only for reduction size) when controlling for car dependency. However, the effects of gender, age, density and income (only for willingness to change) remained after controlling for car dependency, although somewhat weaker effects were measured, suggesting that factors other than the (in)ability to use other travel modes play a role. Possible explanations might relate to activity rescheduling options - e.g., younger people have more flexible activity schedules, as they often have fewer household responsibilities - or activity locations - e.g., people living in more-urbanised areas having more facility options closer to their homes. Of course, attitudes and preferences could have affected responses as well (Schwanen and Mokhtarian, 2005; Steg, 2005; Jensen, 1999). In a next step, we will analyse car dependency at the trip level and operationalise it in more detail - i.e., measure it relative to various change options - which will enable us to more thoroughly understand car use change as structured by concrete adaptation constraints and capacities. Additionally, we will consider the effect of attitudes towards car use and subjective evaluations of the TDC measure on behavioural change.

Unlike most road pricing studies to date, this study included the density of participants' residential area as an explanatory variable, as level of urbanisation is an important factor in people's mode choices and distances travelled (e.g., Dieleman et al., 2002). Density appeared to have a significant effect, with people living in weakly or non-urbanised areas reporting lower reduction levels. This shows that spatial context is a relevant factor in behavioural change in response to pricing measures that should not be overlooked in the road pricing literature. Indicators of accessibly to facilities and public transport and geographical information about frequently visited locations, such as work locations, might add explanatory power to car use reduction models in future research.

The web application used in this research is a promising tool for further research on understanding travel behaviour adaptations in other contexts. The tool was able to capture multidimensional adaptations by allowing participants to reorganise their complete activity/trip schedule, thus producing more realistic data and enhancing daily car use decision-making understanding, as the majority of quantitative techniques that have been designed to date to measure car use change rely on mutually exclusive change options. However, the application might have been too complex and demanding for some participants, as some who made adaptations in the first scenario did not make many adaptations in the second scenario. Additionally, the dropout rate during the experiment was higher for lower-educated participants. Also, although it was tried to keep the application as simple as possible, participants might have experienced certain adaptation strategies to be easier to select than other options. For example, cancelling an activity or selecting an alternative travel mode could be selected by just one click in the experiment, whereas more effort was needed 
to reschedule an activity (deleting an old activity and creating a new activity on another day) and to create multimodal trips (requiring to insert a transfer location). Although this might have influenced participants' decisions, many people made rather complex adaptations at the same time, suggesting that people generally understood the application, were fully engaged with the experiment and felt encouraged to make realistic and feasible decisions.

In this study we covered only one week. Having results based on such a multiday time span is an important advantage compared to many stated preference experiments that are based on only one trip or one day, which consequently are not able to capture complex interrelationships between activity needs and travel patterns over subsequent days. Still, covering an even longer period of time, with a potential less intrusive research technique, is valuable as one might find it easier to change trips in one week than over a longer period of time. For example, people might have cancelled their trip in our experiment because they decided just to postpone the activity, meaning that the activity would have to return in a later stage. Further, as our study only investigated short-term effects, future research should also take into account possible longer-term adaptation strategies people wish to make, such as decisions to buy an e-bike, to get a public transport subscription, to work closer to home, or to relocate (Tillema et al., 2010; Arentze and Timmermans, 2007). The selection of such alternatives might have consequences for the occurrence of the short-term effects studied in this experiment. Nevertheless, this study showed that financial rewards/losses, even though relatively small, are an effective way of making people to modify travel behaviours with the means often directly available to them.

\section{Acknowledgements}

This research was funded by 'The Application of Operations Research in Urban Transport' programme of the Netherlands Organisation for Scientific Research (grant 435-12-212). We thank the two anonymous reviewers for their valuable comments on an earlier draft of the paper.

\section{References}

Arentze, T.A., Timmermans, H.J.P., 2007. Congestion pricing scenarios and change of job or residential location: results of a stated adaptation experiment. J. Transp. Geogr. 15, 56-61.

Arentze, T., Hofman, F., Timmermans, H., 2004. Predicting multi-faceted activity-travel adjustment strategies in response to possible congestion pricing scenarios using an Internet-based stated adaptation experiment. Transp. Policy 11, 31-41.

Axhausen, K., Gärling, T., 1992. Activity-based approaches to travel analysis: conceptual frameworks, models and research problems. Transp. Rev. 12, 324-341. Bao, Y., Gao, Z., Xu, M., Yang, H., 2014. Tradable credits scheme for mobility management considering travelers' loss aversion. Transp. Res. Part E 68, 138-154. Baumol, W., Oates, W., 1988. The Theory of Environmental Policy. Cambridge University Press, Cambridge.

Bonsall, P., Shires, J., Maule, J., Matthews, B., Beale, J., 2007. Responses to complex pricing signals: theory, evidence and implications for road pricing. Transport. Res. Part A 41, 672-683.

Bristow, A.L., Wardman, M., Zanni, A.M., Chintakayala, P.K., 2010. Public acceptability of personal carbon trading and carbon tax. Ecol. Econ. 69, 1824-1837. Buitelaar, E., van der Heijden, R., Argiolu, R., 2007. Managing traffic by privatization of road capacity: a property rights approach. Transp. Rev. 27, 699-713. Capstick, S.B., Lewis, A., 2010. Effects of personal carbon allowances on decision-making: Evidence from an experimental simulation. Climate Policy 10, 369-384. CBS, 2017. Hoogst behaald onderwijsniveau. Den Haag/Heerlen, CBS. Retrieved from statline.cbs.nl.

Clay, M.J., Mokhtarian, P.L., 2004. Personal travel management: the adoption and consideration of travel-related strategies. Transport. Plan. Tech. 27, 181-209. Coase, R.A., 1960. The problem of social cost. J. Law Econ. 3, 1-44.

Costello, C., Gaines, S.D., Lynham, J., 2008. Can catch shares prevent fisheries collapse? Science 321, 1678-1681.

Crals, E., Keppens, M., Vereeck, L., 2003. Tradable fuel permits: towards a sustainable transport system. In: Wulfhorst, J.D., Haugestad, A.K. (Eds.), Future as Fairness: Ecological Justice and Global Citizenship. Rodopi, Amsterdam.

Cramton, P., Kerr, S., 2002. Tradeable carbon permit auctions: how and why to auction not grandfather. Energy Policy 30, 333-345.

Davis, L.W., 2008. The effect of driving restrictions on air quality in Mexico City. J. Pol. Econ. 116, 38-81.

Dieleman, F., Dijst, M., Burghouwt, G., 2002. Urban form and travel behaviour: micro-level household attributes and residential context. Urban Stud. 39, 507-527. Dijst, M., 2009. Time geographical analysis. In: Kitchin, R., Thrift, N. (Eds.), Int. Encyclopaedia Hum. Geogr. Elsevier, Oxford, pp. $266-278$.

Dogterom, N., Ettema, D., Dijst, M., 2017. Tradable credits for managing car travel: a review of empirical research and relevant behavioural approaches. Transp. Rev. $37,322-343$.

Ettema, D.F., Timmermans, H.J.P. (Eds.), 1997. Activity-based Approaches to Travel Analysis. Pergamon, Oxford.

Faivre d'Arcier, B., Andan, O., Raux, C., 1998. Stated adaptation surveys and choice process: some methodological issues. Transportation 25, 169-185.

Fan, W., Jiang, J., 2013. Tradable mobility permits in roadway capacity allocation: review and appraisal. Transp. Policy 30, $132-142$.

Fawcett, T., 2010. Personal carbon trading: a policy ahead of its time? Energy Pol.

Fawcett, T., Parag, Y., 2010. An introduction to personal carbon trading. Clim. Pol. 10, 329-338.

Franke, A., Kaniok, D., 2013. Responses to differentiated road pricing schemes. Transport. Res. Part A 48, 25-30.

Gehlert, T., Kramer, C., Nielsen, O.A., Schlag, B., 2011. Socioeconomic differences in public acceptability and car use adaptation towards urban road pricing. Transp. Policy 18, 685-694.

Girod, B., van Vuuren, D.P., de Vries, B., 2013. Influence of travel behaviour on glocal CO2 emissions. Transp. Res. Part A 50, $183-197$.

Goddard, H., 1999. Promoting urban sustainability: the case for a tradable supplementary licence system for vehicle use. Urban Stud. 36, $2317-2331$.

Goodwin, P., Dargay, J., Hanly, M., 2004. Elasticities of road traffic and fuel consumption with respect to price and income: a review. Transp. Rev. 24, 275-292.

Graham, D.J., Glaister, S., 2004. Road traffic demand elasticity estimates: a review. Transp. Rev. 24, $261-274$.

Grant-Muller, S., Xu, M., 2014. The role of tradable credit schemes in road traffic congestion management. Transp. Revi. 34, 128-149.

Hägerstrand, T., 1970. What about people in regional science? Papers Region. Sci. Assoc. 24, 7-21.

Hahn, R.W., Hester, G., 1989. Marketable permits: lessons for theory and practice. Ecol. Law Quart. 16, 361-406.

Hao, H., Wang, H., Ouyang, M., 2011. Comparison of policies on vehicle ownership and use between Beijing and Shanghai and their impacts on fuel consumption by passenger vehicles. Energy Pol. 39, 1016-1021.

Harwatt, H., Tight, M., Bristow, A.L., Gühnemann, A., 2011. Personal Carbon Trading and fuel price increases in the transport sector: an exploratory study of public response in the UK. Eur. Transp. 47, 47-70.

Hepburn, C., 2006. Regulation by price, quantities, or both: a review of instrument choice. Oxford Rev. Econ. Pol. $22,226-247$.

Jaensirisak, S., Wardman, M., May, A.D., 2005. Explaining variations in public acceptability of road pricing schemes. J. Transp. Econ. Pol. 39, 127-153.

Jensen, M., 1999. Passion and heart in transport - a sociological analysis on transport behaviour. Transp. Policy 6, 19-33.

Jones, P., Dix, M.C., Clarke, M.I., Heggie, I.G., 1983. Understanding Travel Behaviour. Gower, Aldershot, UK.

Kahneman, D., Tversky, A., 1979. Prospect theory: an analysis of decision under risk. Econometrica 47, $263-292$. 
Kitamura, R., 1988. An evaluation of activity-based travel analysis. Transportation 15, 9-34.

Kockelman, K.M., Kalmanje, S., 2005. Credit-based congestion pricing: a policy proposal and the public's response. Transp. Res. Part A 39, 671-690.

Lee-Gosselin, M.E.H., 1996. Scope and potential of interactive stated response data collection methods. In: Household travel surveys: new concepts and research needs. Conference Proceedings 10, Transportation Research Board, Washington D.C.

Loukopoulos, P., Jakobsson, C., Gärling, T., Meland, S., Fujii, S., 2006. Understanding the process of adaptation to car-use reduction goals. Transp. Res. Part F 9, $115-127$.

Mayeres, I., Proost, S., 2004. Reforming transport pricing: an economist's perspective on equity, efficiency and acceptability. In: Schade, J., Schlag, B. (Eds.), Acceptability of Transport Pricing Strategies. Elsevier, Oxford.

Mokhtarian, P.L., Raney, E.A., Salomon, I., 1997. Behavioral response to congestion: identifying patterns and socio-economic differences in adoption. Transp. Policy 4 , $147-160$.

Montgomery, W., 1972. Markets in licenses and efficient pollution control programs. J. Econ. Theor. 5, 395-418.

Nie, Y., 2012. Transaction costs and tradable mobility credits. Transp. Res. Part B 46, 189-203.

Nijland, E.W., Arentze, T.A., Borgers, A.W.J., Timmermans, H.J.P., 2009. Individuals' activity-travel rescheduling behaviour: experiment and model-based analysis. Environ. Plan. A 41, 1511-1522.

Odeck, J., Bråthen, S., 1997. On public attitudes toward implementation of toll roads - the case of Oslo toll ring. Transp. Policy 4, 73-83.

Parag, Y., Capstick, S., Poortinga, W., 2011. Policy attribute framing: a comparison between three policy instruments for personal emissions reduction. J. Pol. Anal. Manage. 30, 889-905.

Pigou, A.C., 1920. Wealth and Welfare. MacMillan, London.

Polk, M., 2004. The influence of gender on daily car use and on willingness to reduce car use in Sweden. J. Transp. Geogr. 12, 185-195.

Pucher, J., Peng, Z.-R., Mittal, N., Zhu, Y., Korattyswaroopam, N., 2007. Urban transport trends and policies in China and India: impacts of rapid economic growth. Transp. Rev. 27, 379-410.

Raux, C., Croissant, Y., Pons, D., 2015. Would personal carbon trading reduce travel emissions more effectively than a carbon tax? Transp. Res. Part D 35, 72-83.

Raux, C., Marlot, G., 2005. A system of tradable CO2 permits applied to fuel consumption by motorists. Transp. Policy 12, 255-265.

Rienstra, S.A., Rietveld, P., Verhoef, E.T., 1999. The social support for policy measures in passenger transport: a statistical analysis for the Netherlands. Transp. Res. Part D 4, 181-200.

Rouwendal, J., Verhoef, E.T., 2006. Basic economic principles of road pricing: from theory to applications. Transp. Pol. 13, 106-114.

Santos, G., Behrendt, H., Maconi, I., Shirvani, T., Teytelboym, A., 2010. Part I: externalities and economic policies in road transport. Res. Transp. Econ. 28, 2-45.

Schade, J., Schlag, B. (Eds.), 2003. Acceptability of Transport Pricing Strategies. Elsevier, Oxford.

Starkey, R., 2012. Personal carbon trading: a critical survey. Part 1: Equity. Ecol. Econ. 73, 7-18.

Steg, L., 2005. Car use: lust and must. Instrumental, symbolic and affective motives for car use. Transp. Res. Part A 39, 147-162.

Schwanen, T., Mokhtarian, P.L., 2005. What affects commute mode choice: neighborhood physical structure or preferences toward neighborhoods. J. Transp. Geogr. $13,83-99$.

Sovacool, B.K., 2011. The policy challenges of tradable credits: a critical review of eight markets. Energy Pol. 39, $575-585$.

Tietenberg, T., 2003. The tradable permits approach to protecting the commons: lessons for climate change. Oxford Rev. Econ. Pol. 19, 400-419.

Tillema, T., 2007. Road Pricing: A Transport Geographical Perspective. PhD thesis. Utrecht University, Utrecht, The Netherlands.

Tillema, T., van Wee, B., Ettema, D., 2010. The influence of (toll-related) travel costs in residential location decision of households: a stated choice approach. Transp. Res. Part A 44, 785-796.

Timmermans, H.J.P. (Ed.), 2005. Progress in Activity-based Analysis. Elsevier, Amsterdam.

Ubbels, B., Verhoef, E., 2005. Behavioural responses to road pricing. Empirical results from a survey among Dutch car owners. Eur. Transp. \Transporti Europei 31 , $101-117$.

Ubbels, B., 2006. Road Pricing. Effectiveness, Acceptance and Institutional Aspects. Free University, Amsterdam, The Netherlands.

van Amelsfort, D., Bovy, P., Bliemer, M., Ubbels, B., 2008. Travellers' responses to road pricing: value of time, schedule delay and unreliability. In: Verhoef, E., Bliemer, M., Steg, L., van Wee, B. (Eds.), Pricing in Road Transport: A Multi-disciplinary Approach. Edward Elgar, Cheltenham, UK.

Verhoef, E., Nijkamp, P., Rietveld, P., 1997. Tradeable permits: their potential in the regulation of road transport externalities. Environ. Plan. B 24, 527-548.

Vickrey, W.S., 1969. Congestion theory and transport investment. Am. Econ. Rev. 59, 251-260.

Viegas, J.M., 2001. Making urban road pricing acceptable and effective: searching for quality and equity in urban mobility. Transp. Pol. 8, $289-294$.

Wadud, Z., 2011. Personal tradable carbon permits for road transport: Why, why not and who wins? Transp. Res. Part A 45, 1052-1065.

Wallace, A.A., Irvine, K.N., Wright, A.J., Fleming, P.D., 2010. Public attitudes to personal carbon allowances: findings from a mixed-method study. Clim. Pol. 10, 385-409.

Washbrook, K., Haider, W., Jaccard, M., 2006. Estimating commuter mode choice: a discrete choice analysis of the impact of road pricing and parking charges. Transportation 33, 621-639.

Xiao, F., Qian, Z., Zhang, H.M., 2013. Managing bottleneck congestion with tradable credits. Transp. Res. Part B 56, 1-14.

Yang, H., Wang, X., 2011. Managing network mobility with tradable credits. Transp. Res. Part B 45, 580-594.

Zanni, A.M., Bristow, A.L., Wardman, M., 2013. The potential behavioural effect of personal carbon trading: results from an experimental survey. J. Environ. Econ. Pol. 2, 222-243. 